\title{
Molecular surveillance for drug-resistant Plasmodium falciparum in clinical and subclinical populations from three border regions of Burma/ Myanmar: cross-sectional data and a systematic review of resistance studies
}

Tyler Brown ${ }^{1,2}$, Linda S Smith², Eh Kalu Shwe Oo ${ }^{3}$, Kum Shawng ${ }^{4}$, Thomas J Lee ${ }^{2,6}$, David Sullivan ${ }^{5}$, Chris Beyrer ${ }^{7}$ and Adam K Richards ${ }^{2,8^{*}}$

\begin{abstract}
Background: Confirmation of artemisinin-delayed parasite clearance in Plasmodium falciparum along the Thai-Myanmar border has inspired a global response to contain and monitor drug resistance to avert the disastrous consequences of a potential spread to Africa. However, resistance data from Myanmar are sparse, particularly from high-risk areas where limited health services and decades of displacement create conditions for resistance to spread. Subclinical infections may represent an important reservoir for resistance genes that confer a fitness disadvantage relative to wild-type alleles. This study estimates the prevalence of resistance genotypes in three previously unstudied remote populations in Myanmar and tests the a priori hypothesis that resistance gene prevalence would be higher among isolates collected from subclinical infections than isolates collected from febrile clinical patients. A systematic review of resistance studies is provided for context.

Methods: Community health workers in Karen and Kachin States and an area spanning the Indo-Myanmar border collected dried blood spots from 988 febrile clinical patients and 4,591 villagers with subclinical infection participating in routine prevalence surveys. Samples positive for $P$. falciparum $18 \mathrm{~s}$ ribosomal RNA by real-time PCR were genotyped for $P$. falciparum multidrug resistance protein (pfmdr1) copy number and the pfcrt K76T polymorphism using multiplex real-time PCR.

Results: Pfmdr 1 copy number increase and the pfcrt K76 polymorphism were determined for 173 and 269 isolates, respectively. Mean pfmdr1 copy number was 1.2 (range: 0.7 to 3.7). Pfmdr1 copy number increase was present in $17.5 \%, 9.6 \%$ and $11.1 \%$ of isolates from Karen and Kachin States and the Indo-Myanmar border, respectively. Pfmdr 1 amplification was more prevalent in subclinical isolates (20.3\%) than clinical isolates (6.4\%, odds ratio 3.7, 95\% confidence interval 1.1 - 12.5). Pfcrt K76T prevalence ranged from 90-100\%.

(Continued on next page)
\end{abstract}

\footnotetext{
* Correspondence: adamrichards@mednet.ucla.edu

${ }^{2}$ Global Health Access Program, 2550 Ninth Street, Ste 111, Berkeley CA 94710, USA

${ }^{8}$ Department of General Internal Medicine and Health Services Research, University of California at Los Angeles, 911 Broxton Ave, Los Angeles CA 90025, USA

Full list of author information is available at the end of the article
} 
(Continued from previous page)

Conclusions: Community health workers can contribute to molecular surveillance of drug resistance in remote areas of Myanmar. Marginal and displaced populations under-represented among previous resistance investigations can and should be included in resistance surveillance efforts, particularly once genetic markers of artemisinin-delayed parasite clearance are identified. Subclinical infections may contribute to the epidemiology of drug resistance, but determination of gene amplification from desiccated filter samples requires further validation when DNA concentration is low.

Keywords: Malaria, Plasmodium falciparum, Artemisinin resistance, Genetic, Subclinical infection, Conflict, Myanmar

\section{Background}

Genetically determined artemisinin-delayed parasite clearance or tolerance, first documented on the ThaiCambodia border, has emerged on the border of Thailand and Myanmar [1,2]. Recently published estimates of malaria mortality trends suggest that the previous spread of chloroquine (CQ) and sulphadoxine-pyrimethamine resistance from Southeast Asia to Africa [3,4] contributed to the large increase in malaria mortality from 1980-2004 [5], and spread of delayed parasite clearance to Africa would represent a global health catastrophe [6].

In recognition of Myanmar's central location between Southeast Asia and Africa, the WHO outlined a countryspecific strategy for Myanmar Artemisinin Resistance Containment (MARC) [7]. The MARC surveillance strategy calls for therapeutic efficacy studies and day-3, parasite-positivity monitoring of artemisinin combination therapy (ACT) in over 20 locations. However, a strategy is lacking to assess drug resistance in remote populations of Myanmar that government and international NGO services have difficulty reaching.

Although molecular markers of artemisinin resistance or delayed parasite clearance have yet to be identified, tracking markers of resistance to partner drugs provides a valuable tool to inform coformulation policy and monitor progress of the Global Plan for Artemisinin Containment (GPARC) and MARC. Clinical and parasitological failure after treatment with an ACT is partially determined by the local efficacy of non-artemisinin partner drugs [8]. Furthermore, the decreased parasiticidal effect of artemisinin along the Myanmar-Thai border places greater reliance on partner drugs. Tracking Plasmodium falciparum multidrug resistance protein ( $p f m d r 1)$ gene copy number (CN) has become an important surveillance tool, particularly in populations receiving artesunate-mefloquine. Pfmdr1 CN is associated with delayed response to ACT, including artesunate-mefloquine [9] and artemetherlumefantrine $[10,11]$, as well as resistance to multiple monotherapy including mefloquine [12-15].

Molecular strategies are particularly valuable for surveillance in remote, displaced and conflict-affected populations facing security and logistical constraints that make conventional in vivo or in vitro resistance studies impractical [16]. Village health workers (VHWs) trained by local community-based organizations play a key role delivering malaria control services in hard-to-access areas of Myanmar [17-19] emerging from decades of conflict, but community based organizations and VHWs have not contributed to past resistance surveillance efforts. Recent studies successfully estimated pfmdr1 (CN) using blood samples collected on filter paper [20], and this simplified protocol makes it possible to extend the quantitative assessment of gene copy number to remote settings lacking the capacity for storage and transport of whole or fractionated blood products.

One question of potential importance in resistance containment is the relative contribution of asymptomatic persons to the reservoir of genetic resistance. Asymptomatic infections provide a parasite reservoir that contributes to malaria transmission even in areas of low or unstable transmission intensity [21-26], but uncertainty exists regarding the role of asymptomatic infections in the transmission of genetic changes conferring drug-resistance. Genetic markers of drug resistance in P. falciparum, including pfcrt K76T haplotypes and pfmdr1 amplification, [27] are associated with decreased parasite fitness and impaired within-host growth [28]. Less fit parasites may be more likely to produce low parasitemia infections that remain asymptomatic. Persistent carriage of resistant parasites in asymptomatic populations is unlikely in situations where multiclonal infections are common, given that more fit parasites with a single copy of $p f m d r 1$ are likely to outcompete less fit parasites with multiple copies of $p f m d r 1$. However, asymptomatic carriage could be favoured in relatively low transmission settings such as those included in this study where host immunity may be insufficient to clear infection and mono-infection with a single resistant clone may be common, particularly if de-amplification of pfmdr $1 \mathrm{CN}$ is rare. In addition, compensatory mutations that decrease the fitness cost of $p f m d r 1$ amplification may allow drug-resistant clones to persist during multiclonal infections. The persistence of drug-resistant infections [29], including multicopy pfmdr1 infections [30], may also be favoured by higher gametocyte carriage that appears to increase their transmission potential relative to drugsensitive, wild-type infections. 
This study sought to assess the feasibility of estimating the prevalence of elevated pfmdr1 $\mathrm{CN}$ and the $p f c r t$ K76T allele in three previously unstudied remote or conflict-affected populations living along Myanmar's borders with India, China and Thailand. This study investigated the contribution of subclinical infections to the epidemiology of genetic resistance by testing the a priori hypothesis that resistance gene prevalence would be higher among isolates collected during active population screening compared to isolates collected from febrile clinical patients. The findings have been situated in context by conducting a systematic review of in vivo, in vitro, and molecular resistance studies in Myanmar and border regions of neighbouring countries. Resistance study locations were mapped relative to areas of recent civil conflict to test the second a priori hypothesis that politically unstable areas would be under-represented among resistance studies in Myanmar.

\section{Methods}

\section{Study sites and participants}

Between February 2009 and January 2010, three community based organizations established 13 surveillance sites in three remote regions of Myanmar: Karen State, Kachin state, and an area spanning the border of Chin State, Myanmar and Mizoram State, India (Figure 1). Populations were selected based on history of malaria burden, feasibility of sample collection, and past exclusion from other surveillance programmes due to inaccessibility or security concerns. Samples were collected by community health workers (CHWs) and VHWs who extend the reach of community-based malaria control services to

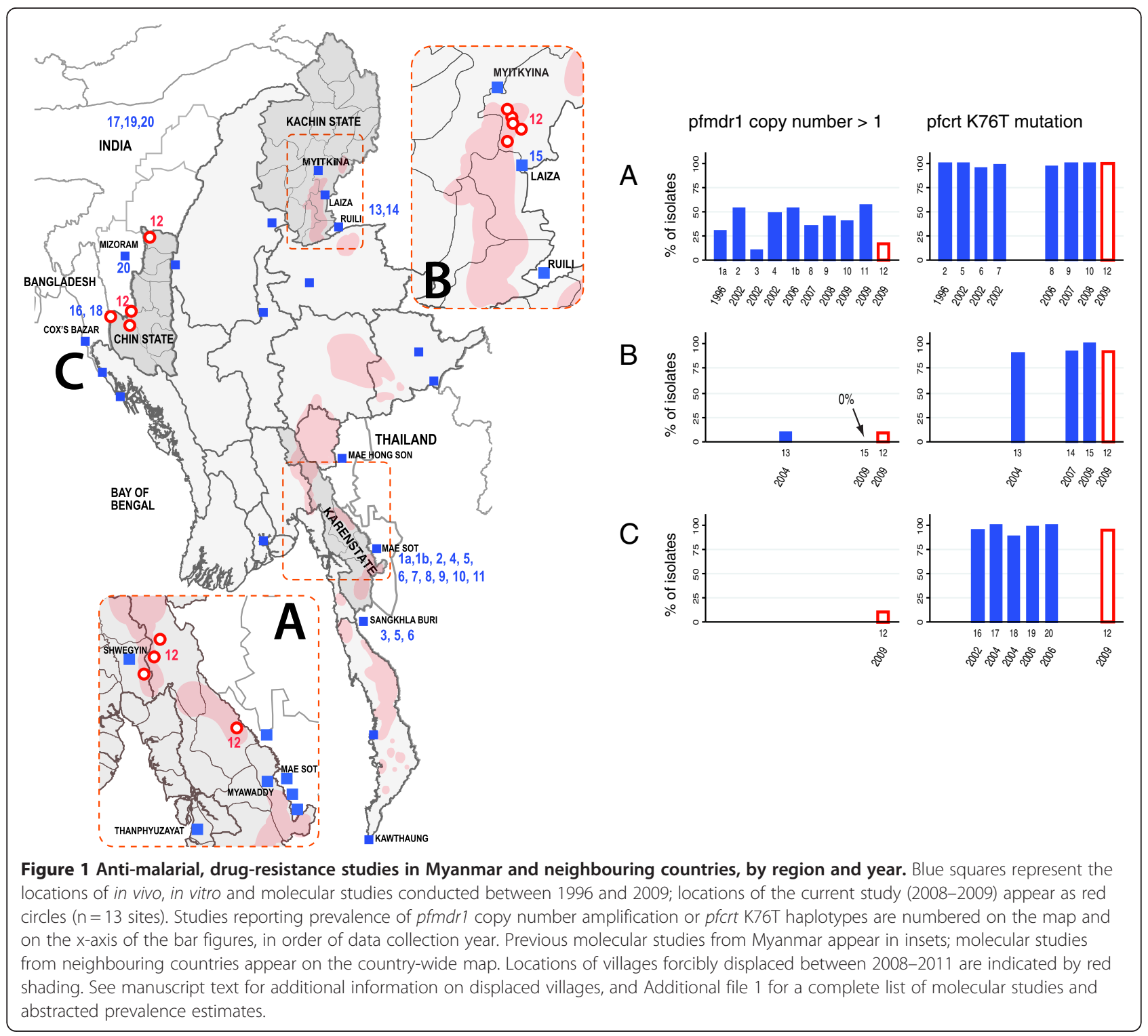


unstable areas, as previously described [18]. The redshaded areas of the map in Figure 1 indicate the locations of villages displaced since 2008 in Karen and Kachin States, where armed conflict was ongoing or imminent, respectively. Sites in border areas of Chin State were located in areas where exposure to human rights violations were widespread [31].

Oral, informed consent was obtained from all participants. Ethical approval for the study was obtained from relevant authorities at each community based organization; Johns Hopkins School of Public Health Committee on Human Subjects approved secondary analysis of the data.

Samples were collected during routine malaria programme activities modified to assess the prevalence of non-P. falciparum species using PCR and validate the use of a $P$. falciparum-specific, histidine-rich protein 2 (HRP-II) based rapid diagnostic test (RDT, Paracheck ${ }^{\circledR}$, Orchid Biomedical Systems, Goa, India) in the setting of clinical diagnosis and population-based screening. CHWs collected blood spots from consecutive clinic patients with self-reported fever and from a subsample of villagers participating in routine bi-annual community malaria prevalence surveys [18,19,32]. All participants were tested for P. falciparum using the RDT and had a blood sample collected on Whatman 903 Protein Saver ${ }^{\circledR}$ cards. The sampling protocol for the programme evaluation was designed to yield approximately $\mathrm{n}=540$ Pf-positive samples: $\mathrm{n}=80$ from febrile clinical patients and $n=100$ from villagers participating in active screenings in each of three regions. Based on a real-time polymerase chain reaction (RT-PCR) budget sufficient to test 2,100 samples, the target sample number for each region was set at 700 (500 screening and 200 clinical). Because historical programme data indicated that $P$. falciparum population prevalence in each region was consistently below $15-20 \%$, the number of screening participants was increased to yield approximately 100 P. falciparum -positive isolates. False-positive RDT results due to persistent HRP-II antigenaemia were expected to approximately offset false-negative RDT results due to low sensitivity in the setting of low parasitaemia infection.

With an expected RDT-positivity rate of approximately $40 \%$, sample collection was anticipated to yield $\sim 80$ P. falciparum -positive isolates from 200 febrile clinical patients in each region. When preliminary results suggested a lower RDT positivity rate (18-33\%), the period of sample collection was extended from two to six months. PCR was performed on all RDT-positive samples and a region-specific fraction of RDT-negative samples from screening participants (22-34\%) and clinic patients $(17 \%-70 \%)$ sufficient to yield approximately $500+200=$ 700 samples for RT-PCR from each region.

\section{DNA extraction and Plasmodium falciparum detection by real-time PCR}

Following an existing protocol [33], DNA was extracted from dried blood samples using a commercial, 96-well, DNA extraction kit from Promega (Madison, Wisconsin, USA). For each sample, DNA from three $5-\mathrm{mm}$ punches (equivalent to approximately $25 \mu \mathrm{L}$ whole blood) was extracted and concentrated four-fold by glycogen-acetate precipitation. Plasmodium falciparum DNA was identified using a validated TaqMan multiplex real-time PCR assay for $P$. falciparum $18 \mathrm{~s}$ ribosomal DNA [33], a molecular method for $P$. falciparum detection that has sensitivity and specificity comparable to nested PCR protocols $[34,35]$. Isolates were considered $P$. falciparum-positive if 18 s PCR end-cycle fluorescence exceeded 300 RFU. All PCR reactions were run in 384-well plates on the Bio-Rad CFX384 Real-Time System (Bio-Rad, Hercules, CA, USA). Primers and probes for TaqMan PCR were synthesized by Integrated DNA Technologies (Coraville, Iowa, USA).

\section{pfmdr1 copy number determination by multiplex real-time PCR}

pfmdr1 copy number was determined using a modification of previous assays [13,36]. Primers and a FAM-labelled probe specific for $p f m d r 1$, plus primers and a Texas Redlabelled probe specific for $P$. falciparum $\beta$-tubulin, were amplified as a multiplex. Each reaction included $\beta$-tubulin primers $(100 \mathrm{nM}), \beta$-tubulin probes $(100 \mathrm{nM})$, pfmdr1 primers (300nM), pfmdr1 probes (200nM), Bio-Rad iQ Multiplex Powermix (1x), and $5 \mu \mathrm{L}$ DNA, in a total reaction volume of $10 \mathrm{ul}$.

Amplification curves were analysed and cycle threshold (Ct) values determined using Bio-Rad CFX Manager software. $p f m d r 1$ copy number was calculated using the predictive efficiency method [36], which corrects the $\Delta \Delta \mathrm{Ct}$ method for differences in amplification efficiency between the reference gene and gene of interest. Genomic DNA from P. falciparum strains 3D7, D10, Dd2 were included as internal controls on each 384-well plate (MR4, Virginia, USA). These strains are known to have one, one, and three to four pfmdr1 copies, respectively. Genomic DNA from 7C424, a strain previously determined to have two copies of $p f m d r 1$, was also used to validate the assay. Mean copy number estimates were 1.15 for $\mathrm{D} 10$ ( $\mathrm{SD}=0.20,32$ repeats), 2.31 for $7 \mathrm{C} 424$ (SD = $0.42,35$ repeats), and 2.98 for $\mathrm{Dd} 2$ ( $\mathrm{SD}=0.39,35$ repeats).

All reactions were run in triplicate and individual replicates were rejected if they did not display exponential kinetics. The precision of $p f m d r 1 \mathrm{CN}$ estimates was calculated for a given isolate as the ratio of the range (maximum-minimum) divided by the mean of isolatespecific replicates $(n=2$ or 3$)$. Copy number estimates were repeated if the difference between replicates was greater than $50 \%$ of the mean estimate, or if the average 
cycle threshold number for $P f \beta$-tubulin was greater than 34. CN estimates were considered invalid if the variance remained greater than $50 \%$ of the mean estimate or $\mathrm{Ct}$ remained greater than 34 after the third repeat.

In the course of the study, a higher proportion of subclinical screening isolates than clinical isolates produced invalid CN estimates. A post-hoc analysis explored the reasons for this discrepancy and assessed the technical feasibility of using filter paper blood samples to estimate $p f m d r 1$ gene copy number in isolates from a predominantly asymptomatic population with relatively low peripheral blood parasite concentrations. Recent evidence suggests that the volume of blood available from filterpaper samples may be insufficient to achieve highly accurate PCR results, particularly when parasitaemia level is low [26]. Current methods to assess gene copy number may be particularly sensitive to DNA concentration, because copy number is a function (ratio) of two quantitative amplification thresholds. Past studies assessed pfmdr1 CN using filter paper-based samples collected from febrile clinical patients [20]; this study explored the feasibility of extending these methods to predominantly asymptomatic infections among active screening participants, and whether the variance in $\mathrm{CN}$ estimates was associated with parasite DNA concentration. The precision of pfmdr $1 \mathrm{CN}$ estimates was plotted against cycle threshold $(\mathrm{Ct})$ values, a proxy for parasitaemia level. $\mathrm{Ct}$ values are inversely proportional to the log DNA concentration in a given isolate, and a three-cycle increase in the $\mathrm{Ct}$ corresponds to approximately a 10-fold decrease in relative concentration of $P$. falciparum DNA.

\section{Detection of pfcrt polymorphisms by multiplex real-time PCR}

Plasmodium falciparum-positive samples were analysed for wild-type pfcrt and pfcrt alleles carrying the K76T polymorphism, using validated primers and probes for the CVIET and CVMNK haplotypes [37]. Each PCR reaction included forward and reverse primers for the $p f c r t$ gene (200nM), a Texas Red-labelled probe specific for the wild-type allele (200nM), a FAM-labelled probe specific for the K76T allele (200nM), Bio-Rad iQ Multiplex Powermix (1x), and $5 \mu \mathrm{L}$ DNA, in a total reaction volume of $10 \mu \mathrm{l}$. Average fluoresence of the last five PCR cycles ("end-cycle fluoresence") was used to determine the presence or absence of the wild-type and K76T polymorphisms. Genomic DNA from the CQ-sensitive D10 and CQ-resistant Dd2 strains were included on each 384-well plate as references. All samples were run in duplicate and criteria for identifying CQ-sensitive parasites were chosen for high specificity. Samples were identified as carrying the wild-type CQ-sensitive allele if both replicates had end-cycle fluorescence greater than $5 \%$ of the range between negative and positive controls.

\section{Statistical analysis}

Data was entered into an ACCESS database using range and consistency checks. Statistical analyses were performed using Stata 12.1. Standard errors were corrected for clustering of the data by village cluster $(n=13)$.

\section{Systematic review of Plasmodium falciparum anti-malarial resistance studies in Burma/Myanmar and its border regions}

PubMed and Google Scholar were searched for clinical, in vitro, and molecular studies evaluating resistance of Plasmodium falciparum to CQ, MQ and ACTs in Myanmar and neighbouring countries. Search terms included "falciparum", "resistance", "efficacy", "Burma", "Myanmar", "Thailand", "China”, "India”, "Bangladesh", "pfmdr1", "pfcrt”, "chloroquine”, "mefloquine”, "lumefantrine", "artemisinin combination therapy", "antimalarial"; and minor variations on these terms. This search generated 860 publications. Reference lists of studies identified in the primary search were searched, as was data from public sources, including WHO Southeast Asia Region and country-specific publications of the WHO and respective Ministries of Health. The review included reports from Bangladesh, India and China if $P$. falciparum isolates were collected from areas bordering Myanmar, and restricted the review to reports published in English after 1995. Only observational and clinical intervention studies and related review articles were included; studies that reported only basic science or methods-oriented findings were excluded. Eighty-two manuscripts met these inclusion criteria. Reports were reviewed for clinical efficacy (failure rates, recrudescence/re-infection, parasite clearance time), in vitro susceptibility data (i e, IC50s) and molecular markers associated with resistance ( $p f m d r 1$ SNPs, $p f m d r 1$ amplification, and the K76T pfcrt mutation) to CQ and MQ monotherapy, and any ACT. Figure 1 shows locations of all studies meeting criteria for this review (blue squares); molecular studies are numbered for reference to the adjacent bar graphs and are listed in Additional file 1. Resistance study locations were determined from published manuscripts and by contacting study authors. Unstable areas of Karen and Kachin States were identified based on evidence of forced displacement of villages since 2008 provided by the Thai-Burma Border Consortium [38] and a community-based organization providing humanitarian assistance in Kachin State (Figure 1).

\section{Results}

Active screening of 4,591 out of 14,982 people living in 13 village-clusters identified 157 isolates positive for P. falciparum $18 \mathrm{~s}$ DNA, and sequential testing of 988 febrile clinical patients identified 133 P. falciparumpositive isolates (Table 1). 
Table 1 Study population characteristics

\begin{tabular}{|c|c|c|c|c|c|c|c|c|}
\hline \multirow[b]{2}{*}{ Number of study sites } & \multicolumn{3}{|c|}{ Study Region } & & & & & \\
\hline & $\begin{array}{l}\text { Karen } \\
4\end{array}$ & $\begin{array}{l}\text { Kachin } \\
5\end{array}$ & $\begin{array}{l}\text { Chin } \\
4\end{array}$ & & & & & \\
\hline \multirow[t]{2}{*}{ Population } & 6176 & 4170 & 4636 & \multicolumn{5}{|c|}{ (Total population: 14,982) } \\
\hline & & & & \multicolumn{5}{|c|}{ Percentage of study participants \% (number) } \\
\hline Study participants ${ }^{b}$ & Karen & Kachin & Chin & $\begin{array}{l}\text { Total study } \\
\text { participants }\end{array}$ & $\begin{array}{l}\text { RDT result } \\
\text { available }^{\mathrm{a}}\end{array}$ & $\begin{array}{l}\text { Pf positive } \\
\text { by RDT }\end{array}$ & $\begin{array}{l}\text { Tested } \\
\text { by PCR }\end{array}$ & $\begin{array}{l}\text { Pf positive } \\
\text { by } P C R\end{array}$ \\
\hline Age $<5$ years & 459 & 284 & 201 & $17 \%(944)$ & $99 \%(938)$ & $13 \%(121)$ & $34 \%(327)$ & $5 \%(49)$ \\
\hline $5-15$ years & 717 & 662 & 522 & $33 \%(1,901)$ & $99 \%(1,881)$ & $15 \%(281)$ & $36 \%(684)$ & $7 \%(138)$ \\
\hline$>15$ years & 996 & 947 & 873 & $50 \%(2,816)$ & $97 \%(2,752)$ & $13 \%(371)$ & $34 \%(964)$ & $4 \%(99)$ \\
\hline Female & 1,152 & 1118 & 801 & $54 \%(3,071)$ & $99 \%(3,038)$ & $12 \%(375)$ & $35 \%(1,070)$ & $4 \%(136)$ \\
\hline $\begin{array}{l}\text { Asymptomatic } \\
\text { screening participants }\end{array}$ & 1,900 & 1,639 & 1,178 & $80 \%(4,717)$ & $97 \%(4,591)$ & $9 \%(430)$ & $32 \%(1,507)$ & $3 \%(157)$ \\
\hline Febrile clinical patients & 536 & 254 & 427 & $20 \%(1,217)$ & $81 \%(988)$ & $35 \%(343)$ & $42 \%(506)$ & $11 \%(133)$ \\
\hline Total participants & 2,436 & 1,893 & 1,605 & 5,934 & $94 \%(5,579)$ & $14 \%(773)$ & $34 \%(2013)$ & $5 \%(290)$ \\
\hline
\end{tabular}

$R D T$ rapid diagnostic test; $P C R$ polymerase chain reaction; Pf Plasmodium falciparum.

${ }^{\text {a }}$ The second round of clinic treatment books in Karen sites were not available to link RDT results to filter-paper blood spots $(n=228)$. All filter samples were eligible for selection for PCR.

${ }^{\mathrm{b}}$ Cells do not add to 5,934 due to missing age and sex data; percentages may not add to $100 \%$ due to rounding.

\section{pfmdr1 copy number}

Of 290 P. falciparum-positive isolates, 173 (59.6\%) were successfully genotyped for $p$ fmdr 1 copy number (Table 2). Thirty-nine percent $(18 / 46)$ of samples from Kachin State, 62\% (115/186) from Chin State, and 80\% (40/50) from Karen State yielded acceptable copy number estimates. Copy number ranged from 0.72 to $3.70 .11 .6 \%$ $(19 / 173,95 \% \mathrm{CI}=2.7-20.4)$ of samples had $>1.5$ copies and $4.6 \%(8 / 173)$ had $>2$ copies. The proportion of isolates with copy number $>1.5(95 \% \mathrm{CI})$ was $9.6 \%$ in Kachin State, $11.1 \%$ in Chin State, and $17.5 \%$ in Karen State (Table 2 and Figure 2). Isolates from population-

Table 2 Pfmdr1 copy number (CN) among subclinical and clinical isolates from three regions of Myanmar 2008-2009

\begin{tabular}{|c|c|c|c|c|c|c|}
\hline & & & & & & \\
\hline & 1 & 2 & 3 & $\overline{4}$ & $(95 \% \mathrm{Cl})^{\mathrm{a}}$ & OR $(95 \% \mathrm{Cl})^{\mathrm{a}}$ \\
\hline Karen State $(n=40)$ & 33 & 6 & 0 & 1 & $17.5(0-54.3)$ & \\
\hline Clinic & 21 & 0 & 0 & 0 & 0.0 & \\
\hline Screening & 12 & 6 & 0 & 1 & 35.0 & n/a \\
\hline Kachin State $(n=18)$ & 16 & 2 & 0 & 0 & $9.6(0-31.6)$ & \\
\hline Clinic & 5 & 1 & 0 & 0 & 16.7 & \\
\hline Screening & 11 & 1 & 0 & 0 & 8.3 & $0.5(0.0-7.8)^{b}$ \\
\hline Chin-Mizoram $(n=115)$ & 104 & 11 & 0 & 0 & $11.1(0-32.1)$ & \\
\hline Clinic & 76 & 6 & 0 & 0 & 7.3 & \\
\hline Screening & 28 & 5 & 0 & 0 & 15.2 & $2.3(1.1-4.7)^{\mathrm{b}}$ \\
\hline Screening vs clinicalTotal $(n=173)$ & 153 & 19 & 0 & 1 & $11.6(2.7-20.4)$ & \\
\hline Clinic & 102 & 7 & 0 & 0 & 6.4 & \\
\hline Screening & 51 & 12 & 0 & 1 & 20.3 & $3.7(1.1-12.5)^{b}$ \\
\hline Anti-malarial treatment Total $(n=168)$ & 148 & 20 & 0 & 1 & & \\
\hline No treatment in past 8 weeks & 117 & 17 & 0 & 1 & 12.7 & \\
\hline Treatment in past 8 wks & 31 & 3 & 0 & 0 & 8.8 & $0.7(0.1-3.1)^{c}$ \\
\hline
\end{tabular}

${ }^{\mathrm{a}} \mathrm{Cls}$ adjusted for clustering within study site $(\mathrm{n}=13)$.

${ }^{\mathrm{b}} \mathrm{OR}=$ odds of $p f m d r 1$ amplification among screening participants/odds of amplification among febrile clinical patients.

${ }^{c} \mathrm{OR}=$ odds among participants reporting treatment in past 8 weeks/odds among those not reporting treatment in previous eight weeks. 
A

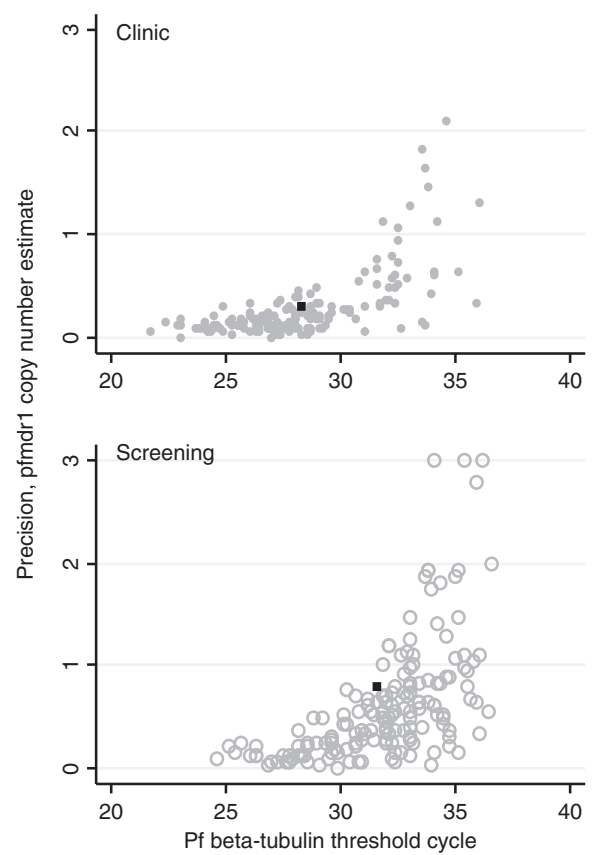

B
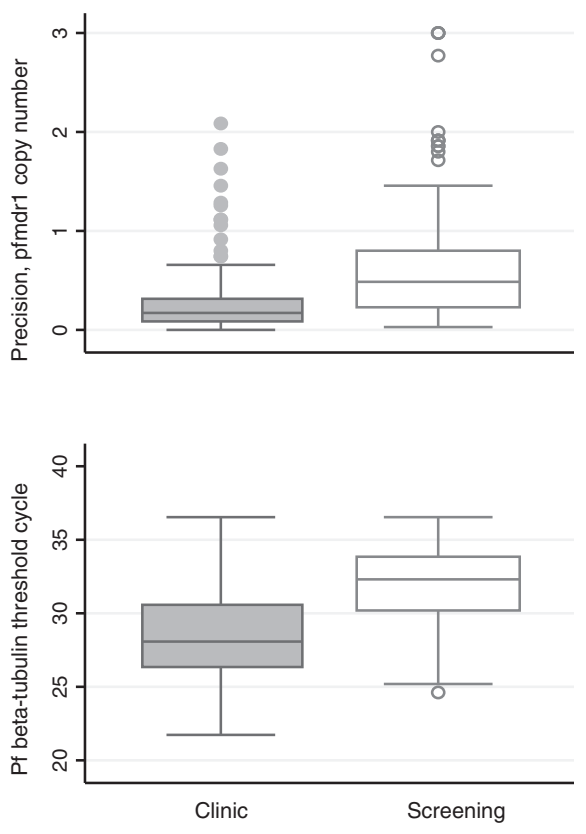

Figure 2 Scatterplots and boxplots of pfmdr1 copy number estimate precision and Plasmodium falciparum beta-tubulin PCR cycle thresholds (Ct) for febrile clinical patients (grey circles and boxplots) and active screening participants (empty circles and boxplots) A: The scatterplots demonstrate precision of pfmdr1 copy number (CN) estimate (y-axis) diminishes as DNA concentration (x-axis) decreases among active screening participants (bottom panel) and febrile clinical patients (top panel). The mean cycle threshold and mean precision of pfmdr $1 \mathrm{CN}$ is indicated by the black point on each scatterplot. A three-cycle increase in the Ct corresponds to a 10-fold decrease in relative concentration of Pf DNA. Pfmdr1 precision is calculated as the range/mean for each isolate, with higher values indicating lower precision. The standard deviation of pfmdr1 CN estimates was 0.200 for clinic patients and .516 for screening participants (not shown) B: Boxplots display the distribution of DNA concentration (top panel) and pfmdr1 CN precision. Boxes represent inter-quartile ranges (IQR); whiskers represent the value of [upper/lower quartile +/- (IQR*1.5)]. Screening participants had lower DNA concentration and less precise estimation of pfmdr1 CN.

screening participants were more likely than those from febrile clinical patients to have elevated pfmdr1 copy number (OR 3.7, 95\% CI 1.1-12.5). There was no difference in $p f m d r 1$ amplification between participants who did and did not report taking anti-malarial treatment in the previous eight weeks.

\section{Pf DNA concentration and precision of pfmdr1 copy number determination}

Of all $\mathrm{CN}$ estimates calculated, including repeat assays, 83 of 157 asymptomatic screening isolates (55\%) and 23 of 133 clinic isolates $(17 \%)$ had range:mean ratios greater than 0.5 and/or mean $P f$ b-tubulin $C t$ values greater than 34, indicating a $P f$ DNA concentration insufficient to estimate $p f m d r 1 \mathrm{CN}$. Precision of pfmdr1 copy number decreased with decreasing P. falciparum DNA concentration (Figure 2). The mean P. falciparum DNA concentration was lower for screening samples than for clinical samples and the precision of copy number estimates was lower overall for screening samples (Figure 2).

\section{pfort wild-type and K76T alleles}

Multiplex PCR detected the wild-type pfcrt allele in 11 of 290 isolates (Table 3). Eight of 186 isolates from surveillance sites in Chin State carried the sensitive allele, as did three of 46 from sites in Kachin State; the sensitive allele was not identified in any of the 57 samples from Karen State. Twenty isolates failed to amplify either the sensitive or the K76T allele. Prevalence of the wild-type $p f c r t$ allele was similar in isolates from active screening participants and febrile clinical patients, and did not vary by report of anti-malarial treatment in the previous eight weeks.

\section{Systematic review}

See Figure 3 and Additional file 1 for results of the brief systematic review of in vivo, in vitro and molecular resistance studies. Half of the 82 resistance studies meeting inclusion criteria were conducted in western Thailand, including all but two studies of $p f m d r 1 \mathrm{CN}$. One study of $p f m d r 1 \mathrm{CN}$ from Myanmar was identified, conducted 
Table 3 Pfcrt genotypes among subclinical and clinical isolates from three regions of Myanmar 2008-2009

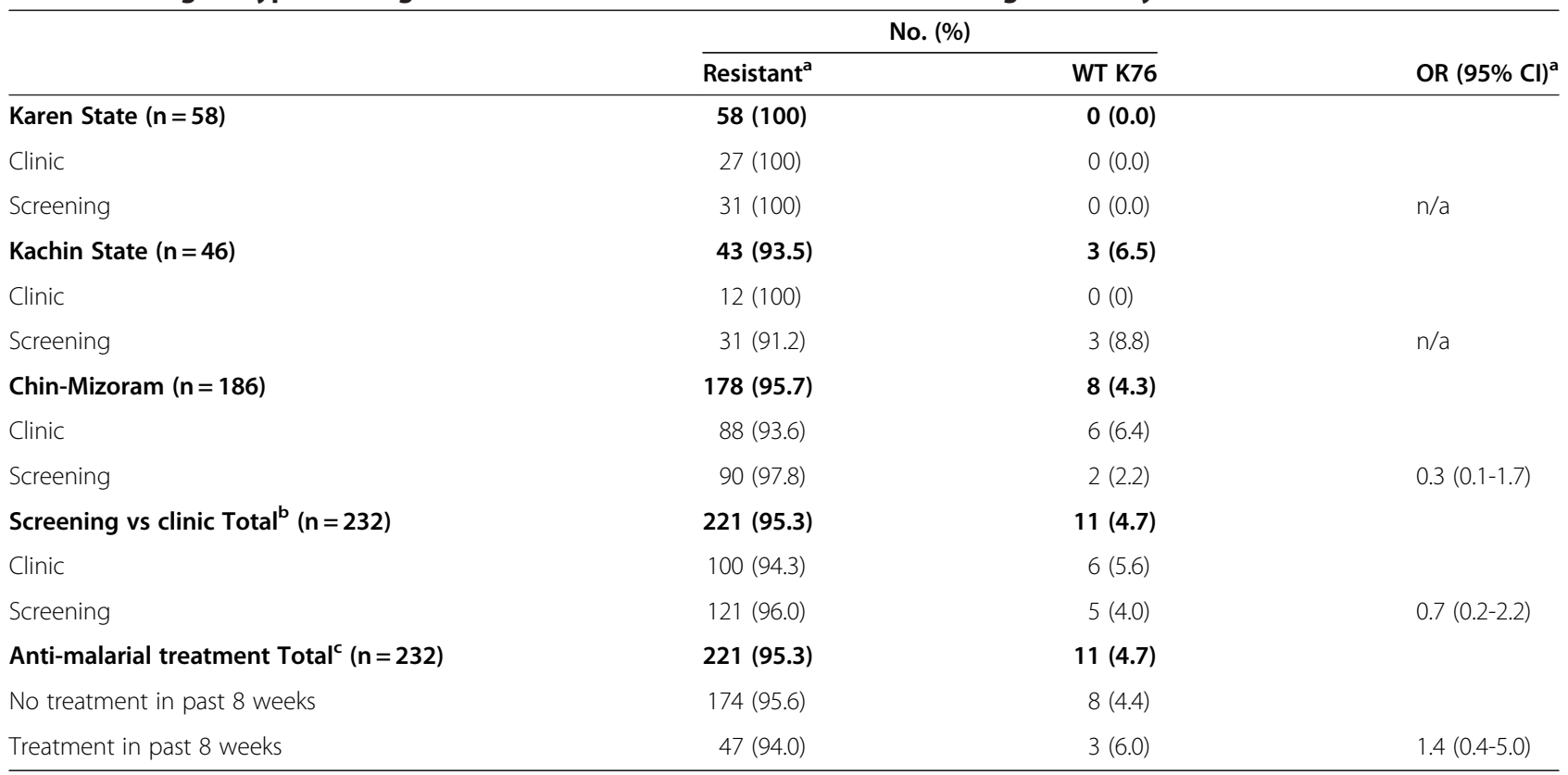

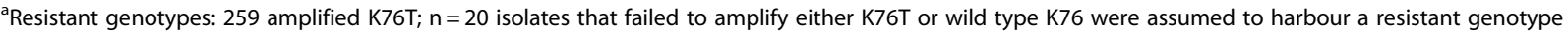
(eg SVMNT). Dropping these 20 observations from the analysis does not qualitatively modify the results.

${ }^{\mathrm{b}} \mathrm{S}$ tandard errors corrected for clustering within village cluster $(\mathrm{n}=13)$.

'Totals exclude Karen State given apparent fixation (100\%) of the K76T allele.

Percentages may not sum to 100 due to rounding.

in Laiza in 2009 (Figure 1B). Locations of in vivo, in vitro and molecular studies did not overlap with areas of instability, indicated forcibly displaced villages (red shading) on the map in Figure 1.

\section{Discussion}

This study demonstrates the feasibility of incorporating a network of health workers affiliated with communitybased organizations into strategies for molecular surveillance of malaria resistance in remote and unstable areas of Myanmar, including priority Tier 1 and Tier 2 areas at high risk for the spread of delayed parasite clearance. This surveillance network can accelerate the assessment of artemisinin resistance and delayed parasite clearance once genetic markers are identified. Myanmar's ecologic, ethnic and political diversity, coupled with patchwork access to malaria control services and quality anti-malarials creates a mosaic of selective drug pressure, and this study provides a preliminary glimpse of patterns emerging over time and place in remote areas of the country, including areas directly across the border from western Thailand where delayed parasite clearance was recently confirmed. The prevalence of $p f m d r 1$ amplification was relatively low (12-19\%) across the three border regions included in the current study; and only a single isolate had a $\mathrm{CN}$ of three or more. Results from Karen State contrast with recent studies documenting elevated $\mathrm{CN}$ in at least $40 \%$ of isolates [9] with a mean $\mathrm{CN}$ of 2.9 (SE 1.4) [39] among refugee, migrant and cross-border populations in Thailand (Figure 1). Findings from Kachin State contrast with a recent study in Laiza that found no pfmdr1 amplification in 171 P. falciparum isolates $[40,41]$, but is consistent with a study conducted in 2004 in nearby counties of Yunnan province [42]. The systematic review failed to identify previous studies of $p f m d r 1 \mathrm{CN}$ along the borders with India and Bangladesh to compare to the $11 \%$ prevalence estimated for that region.

Multiple factors likely contribute to the observed variation in pfmdr1 amplification documented within and between populations living in Myanmar and across its borders in neighbouring countries. Little is known about host response in populations in Myanmar [24], but host immunity is likely to be relatively more robust given higher transmission intensity compared to western Thailand and Yunnan, where migrants from Myanmar account for the majority of infections [19,43-46]. Selective drug pressure also varies substantially due to differences in access to quality diagnosis and treatment. Populations included in the present study live in areas that government and international NGO health services largely fail to reach, and community based organizations are unique providers of malaria control interventions. The low prevalence of pfmdr1 amplification in Karen study sites may be due in part to these malaria 
Myanmar ( $n=12 ; 15 \%$ of studies: nine in vivo, one in vitro and one molecular; the MARC reviews unpublished findings)

- Direct evidence of artemisinin resistance is lacking, although preliminary in vitro data from southern Myanmar suggests emerging tolerance to $\mathrm{AL}$ and $\mathrm{DHQ}[7]$

- In published in vivo studies, ACTs remain highly efficacious (clinical failure rates below 3\%) [60-63] - MQ monotherapy is less effective in clinical trials, with higher 42-day failure rates than ACT. [62] In vitro resistance to $M Q$ appears to be highest near the border with Thailand [64]

- Molecular studies are limited. A single study from Laiza Township, Kachin State found all P. falciparum isolates carried the mutant K76T allele (CVIET); all isolates harboured a single copy of pfmdr1 [39]

\section{Western Thailand ( $\mathrm{n}=41 ; 50 \%$ studies)}

- Genetically-determined resistance to ART, measured by average parasite clearance time and the proportion slow-clearing infections during ART treatment, was recently confirmed in western Thailand [1]

- Clinical efficacy of MAS3, the standard first line treatment for uncomplicated P. falciparum infections, remains high but has declined slightly since 1995 [65]

- Resistance to MQ monotherapy emerged shortly after introduction in 1985 [66]. Introduction of MAS3 may have slowed or reversed the decline in clinical efficacy of MQ [67]

- pfmdr1 amplification is associated with resistance to MQ, ART monotherapy, and MAS combination therapy. $[9,10]$ The prevalence of pfmdr1 amplification has increased since 1996, $[9,10,13,65$, 68-70] but does not appear to explain increasing tolerance to ACTs over time $[1,65]$

- $\mathrm{CQ}$ resistance is widespread and multiple studies document fixation of the pfcrt K76T mutation. [9, $13,68,71]$

\section{Yunnan Province, China ( $n=6,7 \%$ of studies)}

- Unpublished studies suggest low-level clinical resistance to ART monotherapy has emerged in south ern Yunnan Province [7], with two- to three-fold increases in resistance parameters between 1988 and 1999. [72]

- In western Yunnan, in vitro resistance to CQ decreased from 100\% in 1982 to $83 \%$ in 2003 [73], although in $200640 \%$ of infections exhibited in vivo resistance to CQ. [73] $90-92 \%$ of isolates carry the pfcrt K76T mutation $[40,74]$

- A single study reported Pfmdr1 amplification in 9.4\% of isolates from southern Yunnan in 2004 [40]

\section{Northeast India ( $\mathrm{n}=11,13 \%$ of studies)}

- Resistance to MQ is rare [75] and ACT appears to be nearly $100 \%$ clinically effective [76]

- $\mathrm{CQ}$ resistance is prevalent in north-east India, with high treatment failure rates observed in states bordering Myanmar: $60 \%$ in Mizoram, $29 \%$ in Nagaland, $80 \%$ in border districts of Arunchai Pradesh - pfcrt K76T mutations are at fixation. [77] Both CVIET and SVMNT haplotypes are prevalent [78]

- The literature review found no published studies on pfmdr1 amplification in this region

\section{Eastern Bangladesh ( $n=10,12 \%$ of studies)}

- MAS and AL remain highly efficacious in the Chittagong Hill Tracts, an area bordering Rakhine State, Myanmar, with 42-day PCR-corrected efficacy rates of $100 \%$ and $97 \%$, respectively [79]

- P. falciparum isolates from the Chittagong Hill Tracts were more susceptible to $C Q$ and ART in vitro compared to isolates from the Thai-Myanmar and Thai-Cambodia borders [80]

- CQ resistance is well established $[79,81]$ and over $95 \%$ of isolates carry the pfcrt K76T mutation [82]

- The literature review found no published studies on pfmdr1 amplification in this region

Figure 3 Systematic review of in vivo, in vitro, and molecular resistance studies in Myanmar and neighbouring countries, 1996-2009 $[1,7,9,10,13,39,40,60-82]$.

programmes [17] that for 10 years have provided directly observed mefloquine-artesunate that may modify selective pressure for $p f m d r 1$ amplification [47].

The $p f c r t$ K76T mutation is a highly predictive marker of CQ resistance [48]. Replacement of K76T mutants with wild-type parasites following withdrawal of drug pressure has forecast the return of CQ clinical efficacy $[49,50]$ and some authors have proposed tracking this mutation to identify populations in which CQ could be used as partner drugs in ACT [51]. The very low prevalence of wild-type $p f c r t$ in the present study is consistent with data from nearby areas and suggests ongoing selective pressure for $C Q$ resistance. Although decades have passed since CQ was officially recommended by Myanmar or any of its neighbours for the treatment of $P$. falciparum infection, CQ remains the treatment of choice for $P$. vivax and presumptive malaria. The use of RDTs capable of identifying both $P$. falciparum and $P$. vivax species may modestly diminish this selective pressure, but tracking the prevalence of wild-type $p f c r t$ is likely to remain a low priority for resistance surveillance for the next several years. However, pfcrt could become an important genetic marker 
if the recommended treatment of $P$. vivax changes from $\mathrm{CQ}$ to $\mathrm{ACT}$ in response to the recent emergence of CQ-resistant $P$. vivax in western Thailand [52,53].

Consistent with the a priori hypothesis, the prevalence of elevated $p f m d r 1 \mathrm{CN}$ was higher among isolates obtained from active screening participants than from isolates obtained from febrile clinical patients. Resistance surveillance currently relies on samples obtained from clinically symptomatic malaria patients; containment efforts may need to more aggressively target subclinical infections that could serve as a reservoir for the spread of drug resistance if future studies validate an association between subclinical infection and resistance alleles. However, there are several reasons to approach this finding with caution. First, to the authors' knowledge this is the first study to evaluate $p f m d r 1 \mathrm{CN}$ in a predominantly asymptomatic population. Zhong et al. [54] found no difference between symptomatic and asymptomatic study volunteers in Kenya in the frequency of pfmdr1 point mutations, or of the K76T mutation of pfcrt. Second, consistent with Zhong et al. the current study found no difference in K76T mutation prevalence between screening and clinical participants, though prevalence of wild-type $p f c r t$ was low in each region and results may be confounded by ongoing CQ drug pressure as described above. Third, a robust empirically derived conceptual model is lacking to adequately capture the complex interactions between transmission intensity, host immunity, drug pressure, fitness cost, compensatory mutations, clonality of infection, de-amplification $[27,55]$ and other factors expected to influence the relative prevalence of resistant and wild-type parasites in clinical and asymptomatic infections. Clonality of infection is likely to play an important role, as described above, but the prevalence of monoclonal infection in Myanmar is poorly quantified. A single study from central Myanmar documented mono-infection in $32 \%$ of clinical isolates [56], but the relevance of these data to asymptomatic populations in border regions is unclear. The final reason to interpret with caution the association between subclinical infection and genetic resistance is the high variance of pfmdr1 CN estimates found among screening participants that led to the exclusion of $55 \%$ of samples. Future studies are needed to validate the accuracy of pfmdr $1 \mathrm{CN}$ estimates based on filter-paper blood samples collected from subclinical populations. Despite these caveats, findings presented here highlight the need to conduct additional studies on the contribution of subclinical infection to the epidemiology of drug-resistant malaria.

Although mosquitoes and migrating humans frequently carry parasites across international boundaries, it is not clear whether findings from neighbouring countries should be extrapolated to populations living in
Myanmar. Individuals seeking care from border clinics by definition have access to diagnostic and treatment protocols and other resources of neighbouring countries that may differ substantially from those available in remote and conflict-affected areas of Myanmar. Additional studies are necessary to determine the appropriate geographic scale for monitoring the spread of drug resistance.

Systematic review of in vivo, in vitro and molecular resistance studies from Myanmar and its border regions identified relatively few data from populations living inside the country, particularly in Tier 1 and 2 areas of highest priority for resistance containment. The paucity of available information is consistent with output from the under-developed health research capacity in the country as a whole: Myanmar ranks $218^{\text {th }}$ out of 224 countries in number of publications in medicine per capita (0.4 per 100,000 people) [57]. Armed conflict and large-scale population displacement are established causes of disruptions in health services and disease surveillance [58], and can result in "stability bias", defined as the "systematic under-sampling of populations and health threats in contexts of conflict and instability" [59]. The lack of overlap between previous resistance study locations and displaced populations in Myanmar documented in the present study suggests that stabilitybias may contribute to within-country distribution of evidence available for resistance surveillance. The analysis presented here highlights areas with documented population displacement, but does not capture all conflict and human rights violations experienced by other communities. For example, approximately $92 \%$ of households in Chin State may experience forced labour [31] and other human rights violations that have been associated with prevalent malaria infection [32]. The instability of sites participating in this study was tragically validated by violent events since data collection completed in 2009: one Karen site and all Kachin sites were displaced due to military attacks. Some health workers have continued to implement disease control interventions in relocated areas; and they remain willing to participate in resistance surveillance activities. One community-based organization is establishing a site to monitor parasite clearance time.

There were several important limitations to this study. Twenty $P$. falciparum isolates did not amplify either wild type or K76T alleles and it is not possible to exclude the presence of other rare resistance alleles such as SVMNK that were not assessed. None of these twenty isolates produced valid copy number estimates, and they do not modify our primary conclusions that $p f m d r 1$ amplification may be more common among subclinical infections, and that that wild type $p f c r t$ remains rare in these three regions of Myanmar. 
The precision of pfindr $1 \mathrm{CN}$ estimates determined from subclinical infections was low for $44 \%$ of isolates, and $16 \%$ of isolates had DNA concentrations below the lower limit of reliable copy number determination, even after four-fold DNA concentration with glycogen-acetate precipitation. As noted above, future studies are necessary to validate the use of filter-paper samples to estimate gene $\mathrm{CN}$ from lowparasitaemia isolates such as those collected from subclinical infections. This study was not designed to elucidate the mechanisms or relative contributions of factors influencing the prevalence of resistant parasites in subclinical populations. For example, clonality of infection was not determined and parasite DNA from prior infections was unavailable to distinguish re-infection from recrudescence.

The cross-sectional design limits causal inference, and findings related to measures of association should be considered preliminary, as noted above. Study participants lived in areas where quality malaria control services were ongoing for three to 8 years, and findings may not apply to intervention-naïve populations. Samples were collected in 2008-2009 and may not reflect the prevalence of resistance markers in 2012. For example, areas of western Thailand north of Maesot, immediately across the border from one of the present study sites, experienced a sharp rise in the proportion of slowclearing parasites between 2008-10 [1,2].

The number of $P$. falciparum-positive isolates (290) was lower than anticipated by the study design (540) despite screening 4,591 villagers and 988 febrile clinical patients. Logistical constraints delayed data collection in Karen and Kachin areas until the lower-transmission, dry-season months of February and March, with extended clinical sampling through June. The study was conducted in areas of active malaria control, and the success of these programmes likely contributed to the low prevalence of P. falciparum and low RDT positivity rates. The smaller than anticipated number of $P$. falciparum positive samples limited the precision of estimates of genotype prevalence in subclinical and clinical infections, and poor statistical power precluded comparisons across geographic regions. Nevertheless, the number of isolates available for genotyping compares favourably to studies conducted in more stable areas, and data from individuals with subclinical $P$. falciparum infections is unique among published studies from this region.

\section{Conclusions}

Networks of community-based health organizations can and should contribute to molecular surveillance of antimalarial drug resistance in remote and unstable areas of Myanmar, including priority Tier 1 and 2 areas at greatest risk for spread of delayed parasite clearance. Desiccated filter paper facilitates accurate estimation of pfmdr1 CN among febrile clinical isolates and extends the potential geographic range of genetic resistance surveillance, but further study is necessary to validate the use of filter paper in the setting of subclinical infections with low parasite DNA concentrations. The increased risk of pfmdr1 amplification observed among active screening participants hints at a plausible and potentially important contribution of subclinical infection to resistance transmission, but further study is necessary to elucidate the epidemiology of drug resistance among predominantly asymptomatic populations. The consistently low prevalence of wild-type pfcrt alleles, documented in this and other studies, is consistent with persistent CQ drug pressure that is unlikely to diminish until treatment protocols specify CQ-free regimens for P. vivax infections. A systematic review of resistance studies revealed a dearth of data from Myanmar, particularly from areas recently experiencing armed conflict and forced displacement. Marginal populations, such as those participating in this study, should be represented in future resistance surveillance efforts, particularly once genetic markers of delayed parasite clearance are identified. Failure to include these at-risk areas may compromize global efforts to monitor and contain the spread of resistance.

\section{Additional file}

Additional file 1: Brown. Supplementary Appendix 1.docx. Peerreviewed cross-sectional studies reporting prevalence estimates for pfmdr1 copy number or pfcrt K76T haplotypes in Burma and adjacent areas of neighboring countries, 1996-2009. Summarizes cross-sectional molecular studies of antimalarial drug resistance included on the map in Figure 1.

\section{Abbreviations}

ACPR: Acceptable Clinical and Parasitological Result; ACT: Artemisinin combination therapy; AL: Artemether-lumefantrine; ART: Artemisinin (eg: artesunate, artemether); CN: Copy number; CQ: Chloroquine;

DHP: Dihydroartemisinin-piperaquine; MAS: Mefloquine artesunate; MQ: Mefloquine; pfcrt: Plasmodium falciparum CQ resistance transporter; pfmdr1: Plasmodium falciparum multidrug resistance protein ( $p f m d r 1$ ).

\section{Competing interests}

All authors declare that they have no competing interests.

\section{Authors' contributions}

TB carried out the laboratory work, conducted data analysis and literature review, and drafted the manuscript. LS assisted with conception and design of the field study, oversaw fieldwork, takes responsibility for the integrity of the field data, and edited the manuscript; EK and KS supervised fieldwork in Karen State and Kachin State, respectively, and critically reviewed the manuscript; DS assisted with the design of the study, supervised PCR laboratory work and critically reviewed the manuscript; TL and CB assisted with the conception and design of the field study and edited the manuscript; AR conceived and designed the study, conducted data analysis and literature review and drafted the manuscript. All authors read and approved the final manuscript.

\section{Acknowledgements}

The authors extend their gratitude to the health workers and study participants that made this investigation possible. We also thank Stephen 
Dumler, Lirong Shi, Stephen Schachterle, and Nishit Bhuva for their assistance with PCR protocols, and Andrea Wirtz, Sue Tuddenham and Darshan Sudarshi for their assistance with the early phases of this study, and Manny Martinez for his technical assistance with the Figures. Fieldwork was supported by the operating budgets of the participating community-based organizations in Myanmar and the Global Health Access Program. The Johns Hopkins Center for Public Health and Human Rights and the Johns Hopkins Malaria Institute contributed labour and expenses to assist with PCR analyses.

\section{Author details}

'Johns Hopkins University School of Medicine, Broadway Research Building, 733 N. Broadway, Suite 147, Baltimore, MD 21205, USA. ${ }^{2}$ Global Health Access Program, 2550 Ninth Street, Ste 111, Berkeley

CA 94710 , USA. ${ }^{3}$ Karen Department of Health and Welfare, PO Box 189, Mae Sot, Tak 63110, Thailand. ${ }^{4}$ Office of the Director of the Health Department, Kachin Baptist Convention 135/Shan Su (South), Myitkyina, Kachin State, Myanmar. ${ }^{5}$ Department of Molecular Microbiology and Immunology, Johns Hopkins Bloomberg School of Public Health 615 North Wolfe St, Room E5628, Baltimore, MD 21205, USA. ${ }^{6}$ School of Medicine, University of California at Los Angeles, 924 Westwood Blvd, Suite 300, Los Angeles, CA 90024, USA. ${ }^{7}$ Department of Epidemiology Johns Hopkins Bloomberg School of Public Health, 615 N. Wolfe St., Suite E7152, Baltimore, MD 21205, USA. ${ }^{8}$ Department of General Internal Medicine and Health Services Research, University of California at Los Angeles, 911 Broxton Ave, Los Angeles CA 90025, USA.

Received: 1 June 2012 Accepted: 15 August 2012

Published: 19 September 2012

\section{References}

1. Phyo AP, Nkhoma S, Stepniewska K, Ashley EA, Nair S, McGready R, Ler Moo C, Al-Saai S, Dondorp AM, Lwin KM, Singhasivanon P, Day NP, White NJ, Anderson TJ, Nosten F: Emergence of artemisinin-resistant malaria on the western border of Thailand: a longitudinal study. Lancet 2012, 379:1960-1966.

2. Cheeseman IH, Miller BA, Nair S, Nkhoma S, Tan A, Tan JC, Al Saai S, Phyo AP, Moo CL, Lwin KM, McGready R, Ashley E, Imwong M, Stepniewska K, Yi P, Dondorp AM, Mayxay M, Newton PN, White NJ, Nosten F, Ferdig MT, Anderson TJ: A major genome region underlying artemisinin resistance in malaria. Science 2012, 336:79-82

3. Dondorp AM, Newton PN, Mayxay M, Van Damme W, Smithuis FM, Yeung S, Petit A, Lynam AJ, Johnson A, Hien TT, McGready R, Farrar JJ, Looareesuwan S, Day NP, Green MD, White NJ: Fake antimalarials in Southeast Asia are a major impediment to malaria control: multinational cross-sectional survey on the prevalence of fake antimalarials. Trop Med Int Health 2004, 9:1241-1246.

4. Takahashi N, Tanabe K, Tsukahara T, Dzodzomenyo M, Dysoley L, Khamlome B, Sattabongkot J, Nakamura M, Sakurai M, Kobayashi J, Kaneko A, Endo H, Hombhanje F, Tsuboi T, Mita T: Large-scale survey for novel genotypes of Plasmodium falciparum chloroquine-resistance gene pfcrt. Malar J 2012, 11:92.

5. Murray CJ, Rosenfeld LC, Lim SS, Andrews KG, Foreman KJ, Haring D, Fullman N, Naghavi M, Lozano R, Lopez AD: Global malaria mortality between 1980 and 2010: a systematic analysis. Lancet 2012, 379:413-431.

6. White NJ, Nosten F, Looareesuwan S, Watkins WM, Marsh K, Snow RW, Kokwaro G, Ouma J, Hien TT, Molyneux ME, Taylor TE, Newbold Cl, Ruebush TK, Danis M, Greenwood BM, Anderson RM, Olliaro P: Averting a malaria disaster. Lancet 1999, 353:1965-1967.

7. $\mathrm{WHO}$ and Department of Health, Myanmar: Strategic Framework for Artemisinin Resistance Containment in Myanmar (MARC) 2011-2015. Myanmar: Department of Health, Myanmar and World Health Organization; 2011.

8. WHO: Global report on antimalarial drug efficacy and drug resistance: 2000-2010. Geneva: World Health Organization; 2010

9. Muhamad P, Phompradit P, Sornjai W, Maensathian T, Chaijaroenkul W, Rueangweerayut $\mathrm{R}$, Na-Bangchang $\mathrm{K}$ : Polymorphisms of molecular markers of antimalarial drug resistance and relationship with artesunatemefloquine combination therapy in patients with uncomplicated Plasmodium falciparum malaria in Thailand. Am J Trop Med Hyg 2011, 85:568-572.

10. Price RN, Uhlemann AC, van Vugt M, Brockman A, Hutagalung R, Nair S, Nash D, Singhasivanon P, Anderson TJ, Krishna S, White NJ, Nosten F: Molecular and pharmacological determinants of the therapeutic response to artemether-lumefantrine in multidrug-resistant Plasmodium falciparum malaria. Clin Infect Dis 2006, 42:1570-1577.

11. Pongtavornpinyo W, Hastings IM, Dondorp A, White LJ, Maude RJ, Saralamba S, Day NP, White NJ, Boni MF: Probability of emergence of antimalarial resistance in different stages of the parasite life cycle. Evol App 2009, 2:52-61.

12. Pickard AL, Wongsrichanalai C, Purfield A, Kamwendo D, Emery K, Zalewski C, Kawamoto F, Miller RS, Meshnick SR: Resistance to antimalarials in Southeast Asia and genetic polymorphisms in pfmdr1. Antimicrob Agents Chemother 2003, 47:2418-2423.

13. Price RN, Uhlemann AC, Brockman A, McGready R, Ashley E, Phaipun L, Patel R, Laing K, Looareesuwan S, White NJ, Nosten F, Krishna S: Mefloquine resistance in Plasmodium falciparum and increased pfmdr1 gene copy number. Lancet 2004, 364:438-447.

14. Picot S, Olliaro P, de Monbrison F, Bienvenu AL, Price RN, Ringwald P: A systematic review and meta-analysis of evidence for correlation between molecular markers of parasite resistance and treatment outcome in falciparum malaria. Malar J 2009, 8:89.

15. Uhlemann AC, Krishna S: Antimalarial multi-drug resistance in Asia: mechanisms and assessment. Curr Top Microbiol Immunol 2005, 295:39-53.

16. Djimde AA, Dolo A, Ouattara A, Diakite S, Plowe CV, Doumbo OK: Molecular diagnosis of resistance to antimalarial drugs during epidemics and in war zones. J Infect Dis 2004, 190:853-855.

17. Richards AK, Banek K, Mullany LC, Lee Cl, Smith L, Oo EK, Lee TJ: Crossborder malaria control for internally displaced persons: observational results from a pilot programme in eastern Burma/Myanmar. Trop Med Int Health 2009, 14:512-521.

18. Lee Cl, Smith LS, Shwe Oo EK, Scharschmidt BC, Whichard E, Kler T, Lee TJ, Richards AK: Internally displaced human resources for health: villager health worker partnerships to scale up a malaria control programme in active conflict areas of eastern Burma. Glob Public Health 2009 4:229-241

19. Richards AK, Smith L, Mullany LC, Lee Cl, Whichard E, Banek K, Mahn M, Shwe Oo EK, Lee TJ: Prevalence of Plasmodium falciparum in active conflict areas of eastern Burma: a summary of cross-sectional data. Confl Health 2007, 1:9.

20. Shah NK, Alker AP, Sem R, Susanti Al, Muth S, Maguire JD, Duong S, Ariey F, Meshnick SR, Wongsrichanalai C: Molecular surveillance for multidrugresistant Plasmodium falciparum, Cambodia. Emerg Infect Dis 2008, 14:1637-1640

21. da Silva-Nunes M, Moreno M, Conn JE, Gamboa D, Abeles S, Vinetz JM, Ferreira MU: Amazonian malaria: asymptomatic human reservoirs, diagnostic challenges, environmentally driven changes in mosquito vector populations, and the mandate for sustainable control strategies. Acta Trop 2012, 121:281-291.

22. Incardona S, Vong S, Chiv L, Lim P, Nhem S, Sem R, Khim N, Doung S, Mercerau-Puijalon O, Fandeur T: Large-scale malaria survey in Cambodia: Novel insights on species distribution and risk factors. Malar J 2007, 6:37.

23. Macauley C: Aggressive active case detection: a malaria control strategy based on the Brazilian model. Soc Sci Med 2005, 60:563-573.

24. Soe S, Khin Saw A, Htay A, Nay W, Tin A, Than S, Roussilhon C, Perignon JL, Druilhe P: Premunition against Plasmodium falciparum in a malaria hyperendemic village in Myanmar. Trans $R$ Soc Trop Med Hyg 2001, 95:81-84.

25. Alves FP, Gil LH, Marrelli MT, Ribolla PE, Camargo EP, Da Silva LH: Asymptomatic carriers of Plasmodium spp. as infection source for malaria vector mosquitoes in the Brazilian Amazon. J Med Entomol 2005, 42:777-779.

26. Proux S, Suwanarusk R, Barends M, Zwang J, Price RN, Leimanis $M$ Kiricharoen L, Laochan N, Russell B, Nosten F, Snounou G: Considerations on the use of nucleic acid-based amplification for malaria parasite detection. Malar J 2011, 10:323.

27. Preechapornkul P, Imwong M, Chotivanich K, Pongtavornpinyo W, Dondorp AM, Day NP, White NJ, Pukrittayakamee S: Plasmodium falciparum pfmdr1 amplification, mefloquine resistance, and parasite fitness. Antimicrob Agents Chemother 2009, 53:1509-1515.

28. Babiker HA, Hastings IM, Swedberg G: Impaired fitness of drug-resistant malaria parasites: evidence and implication on drug-deployment policies. Expert Rev Anti Infect Ther 2009, 7:581-593. 
29. Barnes Kl, White NJ: Population biology and antimalarial resistance: the transmission of antimalarial drug resistance in Plasmodium falciparum. Acta Trop 2005, 94:230-240.

30. Price RN, Nosten F, Luxemburger C, ter Kuile FO, Paiphun L, Chongsuphajaisiddhi T, White NJ: Effects of artemisinin derivatives on malaria transmissibility. Lancet 1996, 347:1654-1658.

31. Sollom R, Richards AK, Parmar P, Mullany LC, Lian SB, lacopino V, Beyrer C: Health and human rights in Chin State Western Burma: a populationbased assessment using multistaged household cluster sampling. PLoS Med 2011, 8:e1001007.

32. Mullany LC, Richards AK, Lee Cl, Suwanvanichkij V, Maung C, Mahn M, Beyrer C, Lee TJ: Population-based survey methods to quantify associations between human rights violations and health outcomes among internally displaced persons in eastern Burma. J Epidemiol Community Health 2007, 61:908-914.

33. Schachterle SE, Mtove G, Levens JP, Clemens EG, Shi L, Raj A, Munoz B, Reller ME, West S, Dumler JS, Sullivan D: Prevalence and density-related concordance of three diagnostic tests for malaria in a region of Tanzania with hypoendemic malaria. J Clin Microbiol 2011, 49:3885-3891.

34. Rosanas-Urgell A, Mueller D, Betuela I, Barnadas C, Iga J, Zimmerman PA, del Portillo HA, Siba P, Mueller I, Felger I: Comparison of diagnostic methods for the detection and quantification of the four sympatric Plasmodium species in field samples from Papua New Guinea. Malar J 2010, 9:361.

35. Hwang SY, Kim SH, Lee GY, Hang VT, Moon CS, Shin JH, Koo WL, Kim SY, Park HJ, Park HO, Kho WG: A novel real-time PCR assay for the detection of Plasmodium falciparum and Plasmodium vivax malaria in low parasitized individuals. Acta Trop 2011, 120:40-45

36. Alker AP, Lim P, Sem R, Shah NK, Yi P, Bouth DM, Tsuyuoka R, Maguire JD, Fandeur T, Ariey F, Wongsrichanalai C, Meshnick SR: Pfmdr1 and in vivo resistance to artesunate-mefloquine in falciparum malaria on the Cambodian-Thai border. Am J Trop Med Hyg 2007, 76:641-647.

37. Sutherland CJ, Haustein T, Gadalla N, Armstrong M, Doherty JF, Chiodini PL: Chloroquine-resistant Plasmodium falciparum infections among UK travellers returning with malaria after chloroquine prophylaxis. J Antimicrob Chemother 2007, 59:1197-1199.

38. Thai Burma Border Consortium: Displaced villages in Eastern Burma 2008-2011.

39. Poyomtip T, Suwandittakul N, Sitthichot N, Khositnithikul R, Tan-ariya P, Mungthin M: Polymorphisms of the pfmdr 1 but not the pfnhe-1 gene is associated with in vitro quinine sensitivity in Thai isolates of Plasmodium falciparum. Malar J 2012, 11:7.

40. Yang Z, Li C, Miao M, Zhang Z, Sun X, Meng H: Multidrug-resistant genotypes of Plasmodium falciparum, Myanmar. Emerg Inf Dis 2011, 17:498-501.

41. Meng H, Zhang R, Yang H, Fan Q, Su X, Miao J, Cui L, Yang Z: In vitro sensitivity of Plasmodium falciparum clinical isolates from the ChinaMyanmar border area to quinine and association with polymorphism in the $\mathrm{Na}+/ \mathrm{H}+$ exchanger. Antimicrob Agents Chemother 2010, 54:4306-4313.

42. Yang Z, Zhang Z, Sun X, Wan W, Cui L, Zhang X, Zhong D, Yan G, Cui L: Molecular analysis of chloroquine resistance in Plasmodium falciparum in Yunnan Province, China. Trop Med Int Health 2007, 12:1051-1060.

43. Zhou G, Sirichaisinthop J, Sattabongkot J, Jones J, Bjornstad ON, Yan G, Cui L: Spatio-temporal distribution of Plasmodium falciparum and $P$. vivax malaria in Thailand. Am J Trop Med Hyg 2005, 72:256-262.

44. Wiwanitkit $\mathrm{V}$ : High prevalence of malaria in Myanmar migrant workers in a rural district near the Thailand-Myanmar border. Scand J Infect Dis 2002, 34:236-237.

45. Carrara VI, Sirilak S, Thonglairuam J, Rojanawatsirivet C, Proux S, Gilbos V, Brockman A, Ashley EA, McGready R, Krudsood S, Leemingsawat S, Looareesuwan S, Singhasivanon P, White N, Nosten F: Deployment of early diagnosis and mefloquine- artesunate treatment of falciparum malaria in Thailand: The Tak malaria initiative. PLoS Med 2006, 3:e183.

46. Zhou SS, Wang Y, Tang LH: [Malaria situation in the People's Republic of China in 2006] (in Chinese). Chinese journal of parasitology \& parasitic diseases 2007, 25:439-441.

47. Uhlemann AC, McGready R, Ashley EA, Brockman A, Singhasivanon P, Krishna S, White NJ, Nosten F, Price RN: Intrahost selection of Plasmodium falciparum pfmdr1 alleles after antimalarial treatment on the northwestern border of Thailand. J Infect Dis 2007, 195:134-141.

48. Djimde A, Doumbo OK, Cortese JF, Kayentao K, Doumbo S, Diourte Y, Coulibaly D, Dicko A, Su XZ, Nomura T, Fidock DA, Wellems TE, Plowe CV:
A molecular marker for chloroquine-resistant falciparum malaria. N Engl J Med 2001, 344:257-263.

49. Kublin JG, Cortese JF, Njunju EM, Mukadam RA, Wirima JJ, Kazembe PN, Djimde AA, Kouriba B, Taylor TE, Plowe CV: Reemergence of chloroquinesensitive Plasmodium falciparum malaria after cessation of chloroquine use in Malawi. J Infect Dis 2003, 187:1870-1875.

50. Laufer MK, Thesing PC, Eddington ND, Masonga R, Dzinjalamala FK, Takala SL, Taylor TE, Plowe CV: Return of chloroquine antimalarial efficacy in Malawi. N Engl J Med 2006, 355:1959-1966.

51. Plowe CV, Roper C, Barnwell JW, Happi CT, Joshi HH, Mbacham W, Meshnick SR, Mugittu K, Naidoo I, Price RN, Shafer RW, Sibley CH, Sutherland CJ, Zimmerman PA, Rosenthal PJ: World Antimalarial Resistance Network (WARN) III: molecular markers for drug resistant malaria. Malar J 2007, 6:121.

52. Phyo AP, Lwin KM, Price RN, Ashley EA, Russell B, Sriprawat K, Lindegardh N, Singhasivanon P, White NJ, Nosten F: Dihydroartemisininpiperaquine versus chloroquine in the treatment of Plasmodium vivax malaria in Thailand: a randomized controlled trial. Clin Infect Dis 2011, 53:977-984.

53. Rijken MJ, Boel ME, Russell B, Imwong M, Leimanis ML, Phyo AP, Muehlenbachs A, Lindegardh N, McGready R, Renia L, Snounou G, Singhasivanon $\mathrm{P}$, Nosten F: Chloroquine resistant vivax malaria in a pregnant woman on the western border of Thailand. Malar J 2011, 10:113.

54. Zhong D, Afrane Y, Githeko A, Cui L, Menge DM, Yan G: Molecular epidemiology of drug-resistant malaria in western Kenya highlands. BMC Infect Dis 2008, 8:105.

55. Chen N, Chavchich M, Peters JM, Kyle DE, Gatton ML, Cheng Q: Deamplification of pfmdr1-containing amplicon on chromosome 5 in Plasmodium falciparum is associated with reduced resistance to artelinic acid in vitro. Antimicrob Agents Chemother 2010, 54:3395-3401.

56. Kang JM, Moon SU, Kim JY, Cho SH, Lin K, Sohn WM, Kim TS, Na BK: Genetic polymorphism of merozoite surface protein-1 and merozoite surface protein-2 in Plasmodium falciparum field isolates from Myanmar. Malar J 2010, 9:131.

57. Mckee M, Stuckler D, Basu S: Where there is no health research: what can be done to fill the global gaps in health research? PLoS Med 2012, 9:e1001209.

58. Gayer M, Legros D, Formenty P, Connolly MA: Conflict and emerging infectious diseases. Emerg Infect Dis 2007, 13:1625-1631.

59. Beyrer C, Terzian A, Lowther S, Zambrano JA, Galai N, Melchior MK: Civil Conflict and Health Information: The Democratic Republic of Congo. In Public Health and Human Rights: Evidence-based Approaches. Edited by Chris B, Pizer HF. Baltimore: Johns Hopkins University Press; 2007:268-285.

60. Smithuis F, Kyaw MK, Phe O, Aye KZ, Htet L, Barends M, Lindegardh N, Singtoroj T, Ashley E, Lwin S, et al: Efficacy and effectiveness of dihydroartemisinin-piperaquine versus artesunate-mefloquine in falciparum malaria: an open-label randomised comparison. Lancet 2006, 367:2075-2085.

61. Smithuis F, Kyaw MK, Phe O, Win T, Aung PP, Oo AP, Naing AL, Nyo MY Myint NZ, Imwong M, Stepniewska K, White NJ: Effectiveness of five artemisinin combination regimens with or without primaquine in uncomplicated falciparum malaria: an open-label randomised trial. Lancet Infect Dis 2010, 10:673-681.

62. Smithuis F, Shahmanesh M, Kyaw MK, Savran O, Lwin S, White NJ: Comparison of chloroquine, sulfadoxine/pyrimethamine, mefloquine and mefloquine-artesunate for the treatment of falciparum malaria in Kachin State, North Myanmar. Trop Med Int Health 2004, 9:1184-1190.

63. Smithuis F, van der Broek I, Katterman N, Kyaw MK, Brockman A, Lwin S, White NJ: Optimising operational use of artesunate-mefloquine: a randomised comparison of four treatment regimens. Trans $R$ Soc Trop Med Hyg 2004, 98:182-192.

64. Wongsrichanalai C, Lin K, Pang LW, Faiz MA, Noedl H, Wimonwattrawatee T, Laoboonchai A, Kawamoto F: In vitro susceptibility of Plasmodium falciparum isolates from Myanmar to antimalarial drugs. Am J Trop Med Hyg 2001, 65:450-455.

65. Carrara VI, Zwang J, Ashley EA, Price RN, Stepniewska K, Barends M, Brockman A, Anderson T, McGready R, Phaiphun L, Proux S, van Vugt M, Hutagalung R, Lwin KM, Phyo AP, Preechapornkul P, Imwong M, Pukrittayakamee S, Singhasivanon P, White NJ, Nosten F: Changes in the treatment responses to artesunate-mefloquine on the northwestern border of Thailand during 13 years of continuous deployment. PLOS One 2009, 4:e4551. 
66. Nosten F, ter Kuile F, Chongsuphajaisiddhi T, Luxemburger C, Webster HK, Edstein M, Phaipun L, Thew KL, White NJ: Mefloquine-resistant falciparum malaria on the Thai-Burmese border. Lancet 1991, 337:1140-1143.

67. Nosten F, van Vugt M, Price R, Luxemburger C, Thway KL, Brockman A McGready R, ter Kuile F, Looareesuwan S, White NJ: Effects of artesunatemefloquine combination on incidence of Plasmodium falciparum malaria and mefloquine resistance in western Thailand: a prospective study. Lancet 2000, 356:297-302.

68. Chaijaroenkul W, Wisedpanichkij R, Na-Bangchang K: Monitoring of in vitro susceptibilities and molecular markers of resistance of Plasmodium falciparum isolates from Thai-Myanmar border to chloroquine, quinine, mefloquine and artesunate. Acta Trop 2010, 113:190-194.

69. Imwong M, Dondorp AM, Nosten F, Yi P, Mungthin M, Hanchana S, Das D, Phyo AP, Lwin KM, Pukrittayakamee S, Lee SJ, Saisung S, Koecharoen K, Nguon C, Day NP, Socheat D, White NJ: Exploring the contribution of candidate genes to artemisinin resistance in Plasmodium falciparum. Antimicrob Agents Chemother 2010, 54:2886-2892.

70. Phompradit P, Wisedpanichkij R, Muhamad P, Chaijaroenkul W, Na-Bangchang K: Molecular analysis of pfatp6 and pfmdr1 polymorphisms and their association with in vitro sensitivity in Plasmodium falciparum isolates from the Thai-Myanmar border. Acta Trop 2011, 120:130-135.

71. Congpuong K, Na Bangchang K, Mungthin M, Bualombai P, Wernsdorfer WH: Molecular epidemiology of drug resistance markers of Plasmodium falciparum malaria in Thailand. Trop Med Int Health 2005, 10:717-722.

72. Yang H, Liu D, Yang Y, Fan B, Yang P, Li X, Li C, Dong Y, Yang C: Changes in susceptibility of Plasmodium falciparum to artesunate in vitro in Yunnan Province, China. Trans R Soc Trop Med Hyg 2003, 97:226-228.

73. Yang H, Yang Y, Yang P, Li X, Gao B, Zhang Z, Yang Z, Cui L: Monitoring Plasmodium falciparum chloroquine resistance in Yunnan Province, China, 1981-2006. Acta Trop 2008, 108:44-49.

74. Zhang GQ, Guan YY, Zheng B, Wu S, Tang LH: Molecular assessment of Plasmodium falciparum resistance to antimalarial drugs in China. Trop Med Int Health 2009, 14:1266-1271.

75. Shah NK, Dhillon GP, Dash AP, Arora U, Meshnick SR, Valecha N: Antimalarial drug resistance of Plasmodium falciparum in India: changes over time and space. Lancet Infect Dis 2011, 11:57-64.

76. Valecha N, Srivastava P, Mohanty SS, Mittra P, Sharma SK, Tyagi PK, Pradhan K, Dev V, Singh R, Dash AP, Sharma YD: Therapeutic efficacy of artemether-lumefantrine in uncomplicated falciparum malaria in India. Malar J 2009, 8:107.

77. Mohapatra PK, Namchoom NS, Prakash A, Bhattacharya DR, Goswami BK, Mahanta J: Therapeutic efficacy of anti-malarials in Plasmodium falciparum malaria in an Indo-Myanmar border area of Arunachal Pradesh. Indian J Med Res 2003, 118:71-76.

78. Awasthi G, Prasad GB, Das A: Population genetic analyses of Plasmodium falciparum chloroquine receptor transporter gene haplotypes reveal the evolutionary history of chloroquine-resistant malaria in India. Int J Parasitol 2011, 41:705-709.

79. van den Broek IV, Maung UA, Peters A, Liem L, Kamal M, Rahman M, Rahman MR, Bangali AM, Das S, Barends M, Faiz AM: Efficacy of chloroquine + sulfadoxine-pyrimethamine, mefloquine + artesunate and artemether + lumefantrine combination therapies to treat Plasmodium falciparum malaria in the Chittagong Hill Tracts, Bangladesh. Trans $R$ SOC Trop Med Hyg 2005, 99:727-735.

80. Noedl H, Socheat D, Satimai W: Artemisinin-resistant malaria in Asia. $N$ Engl J Med 2009, 361:540-541.

81. Noedl H, Faiz MA, Yunus EB, Rahman MR, Hossain MA, Samad R, Miller RS, Pang LW, Wongsrichanalai C: Drug-resistant malaria in Bangladesh: an in vitro assessment. Am J Trop Med Hyg 2003, 68:140-142.

82. van den Broek IV, van der Wardt S, Talukder L, Chakma S, Brockman A, Nair S, Anderson TC: Drug resistance in Plasmodium falciparum from the Chittagong Hill Tracts, Bangladesh. Trop Med Int Health 2004, 9:680-687.

doi:10.1186/1475-2875-11-333

Cite this article as: Brown et al:: Molecular surveillance for drug-resistant Plasmodium falciparum in clinical and subclinical populations from three border regions of Burma/Myanmar: cross-sectional data and a systematic review of resistance studies. Malaria Journal 2012 11:333.

\section{Submit your next manuscript to BioMed Central and take full advantage of:}

- Convenient online submission

- Thorough peer review

- No space constraints or color figure charges

- Immediate publication on acceptance

- Inclusion in PubMed, CAS, Scopus and Google Scholar

- Research which is freely available for redistribution

Submit your manuscript at www.biomedcentral.com/submit 